Feigning major trauma leads to a time consuming and expensive response from the ambulance service and receiving hospital, and therefore it is vital that any such patients are identified and confronted to deter further similar episodes. In some patients, psychiatric referral may be useful. Our patient has not been seen here or elsewhere in the area for the seven months since he was confronted.

It cannot be emphasised too strongly, however, that the same care must be taken to rule out injury in suspected Munchausen syndrome cases as for any other patient, using ATLS guidelines, before confrontation. There are times when injury cannot be ruled out in such patients - for example to the cervical spine, if the patient persistently complains of pain and tenderness over the vertebrae - and such patients must be admitted for further investigation.
The current standard system for identification of these patients is a handwritten "black book", consulted by staff once suspicions are aroused. We would recommend that all computerised $A \& E$ departments transfer these manual "hospital hopper" records onto computer so that staff are alerted automatically when such patients register. For previously unknown cases, it is essential that staff take the trouble to investigate and inform other hospitals in the area of their findings. Has the time come for a national register of patients with Munchausen syndrome?

1 Asher R. Munchausen's Syndrome. Lancet 1951;i:339-43. Ireland P, Sapira JD, Templeton B. Munchausen's syndrome: a review and a report of an additional case. $\mathrm{Am}$ f Med 1967;43;579-82

3 Banerjee AK. Trauma and Munchausen's syndrome. Arch Emerg Med 1991;8:217-8.

\title{
Hair thread tourniquet syndrome
}

\author{
R Y L Liow, P Budny, P J Regan
}

\begin{abstract}
Tourniquet of hair and thread fibres may become tightly wrapped around a child's digit. The resultant ischaemia may lead to tissue necrosis and autoamputation. Experience with two patients is reported. The need for prompt recognition and complete removal of all fibres is stressed. The possibility of non-accidental injury should be born in mind.

(f Accid Emerg Med 1996;13:138-139)
\end{abstract}

Key terms: digit; hair thread tourniquet syndrome

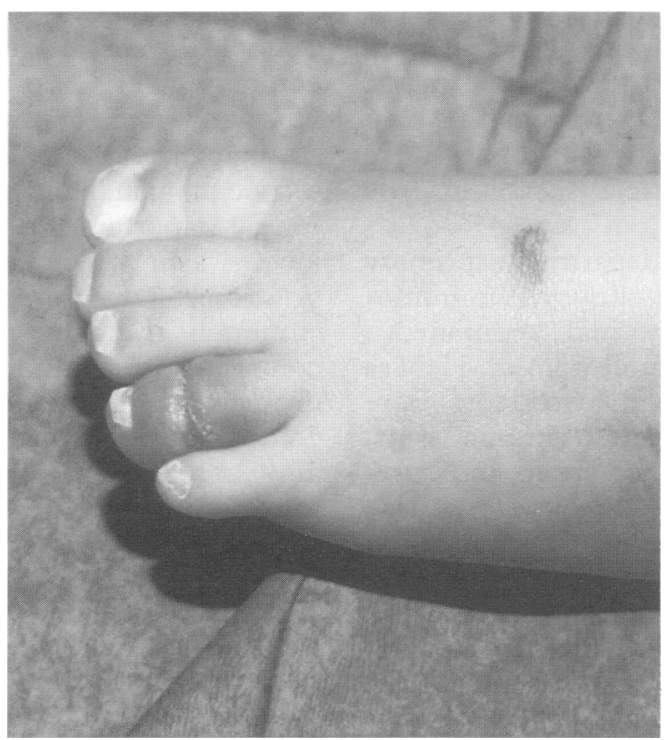

Figure 1 Constricting ring around the left fourth toe producing distal swelling and discolouration. There is no external sign of the causative hair.

\section{Case reports}

CASE 1

An 18 month old girl was referred to us with mild fever and swelling and redness in the left fourth toe (fig 1). She initially presented to the accident and emergency (A\&E) department one month previously when a ring of hair was removed from the toe and the wound dressed. Further pieces of hair were removed by the general practitioner in the ensuing weeks.

Examination revealed a tight hair tourniquet proximal to the distal interphalangeal joint, with marked distal venous congestion. A knotted hair loop was removed surgically (figs 2

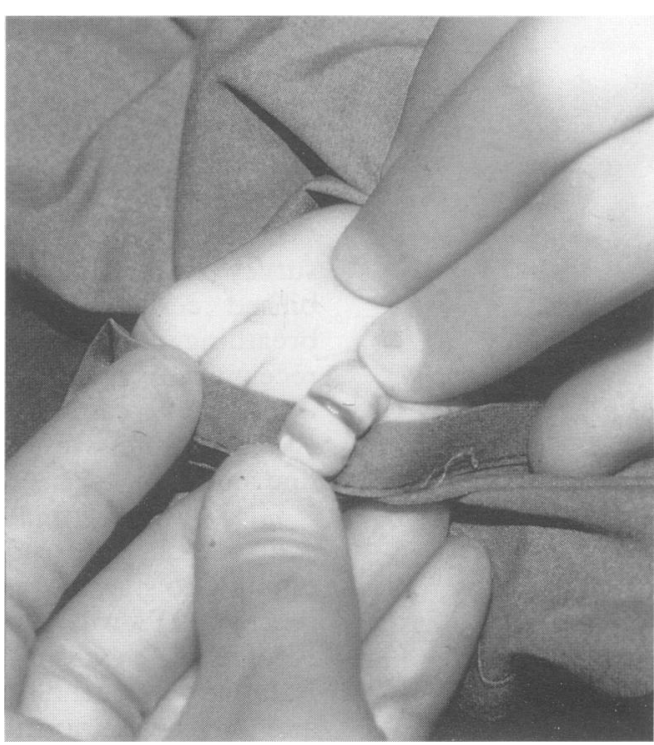

Figure 2 Following the removal of the hair, a tight constricting fibrosis remains.
Correspondence to:

R Y L Liow, Senior House Officer.

Department of Plastic
and Reconstructive
Surgery, Stoke
Mandeville Hospital,
Aylesbury,
Bucks HP21 8AL,
United Kingdom
R Y L Liow
P Budny
P J Regan
Correspondence to:
R Y Liow, Senior House
Officer.




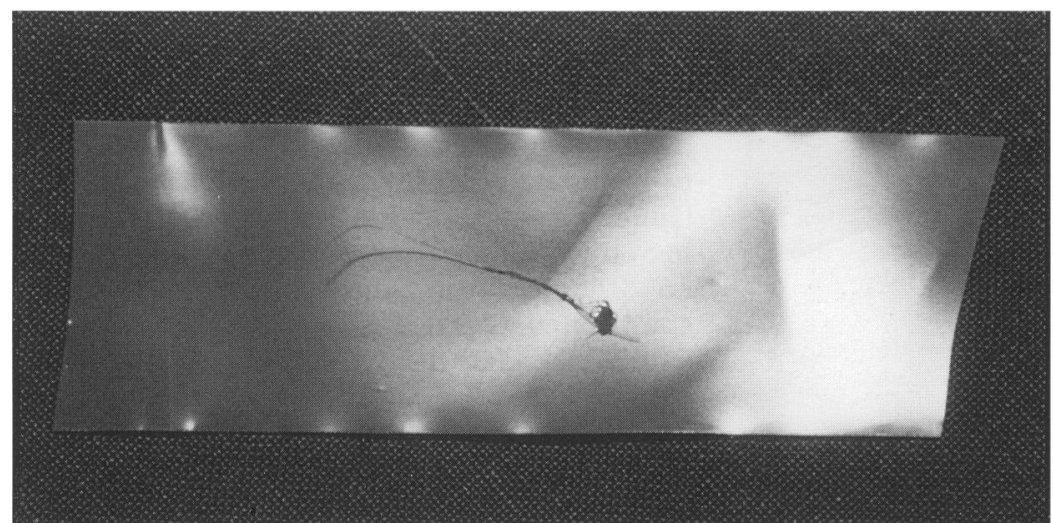

Figure 3 The hair tourniquet. Note the multiplicity of strands.

and 3) and Z-plasty fashioned over the dorsal skin in anticipation of constrictive scarring (fig 4). The toe healed uneventfully.

\section{CASE 2}

A three month old boy was referred with a two day history of irritability and swollen right second toe. A subcutaneous hair thread tourniquet was found and removed. Congestion subsided over the next few days. The toe healed well with conservative wound care.

\section{Discussion}

There have been 67 previous reports of "hair thread tourniquet syndrome" involving fingers, toes, and the external genitalia. ${ }^{12}$ The mechanism of injury is the impairment of lymphatic drainage by the constricting hair or thread. Strangulation becomes established with obstruction to the venous outflow and the arterial inflow. The tourniquet of hair or thread eventually cuts through the oedematous skin and becomes embedded deep in the subcutaneous tissue. Skin epithelialisation can occur to completely bury the tourniquet. The swollen, discoloured and cool appendage eventually undergoes necrosis and may autoamputate.

Prompt and complete removal of all constricting material is essential. Surgical exploration must be considered mandatory if doubt

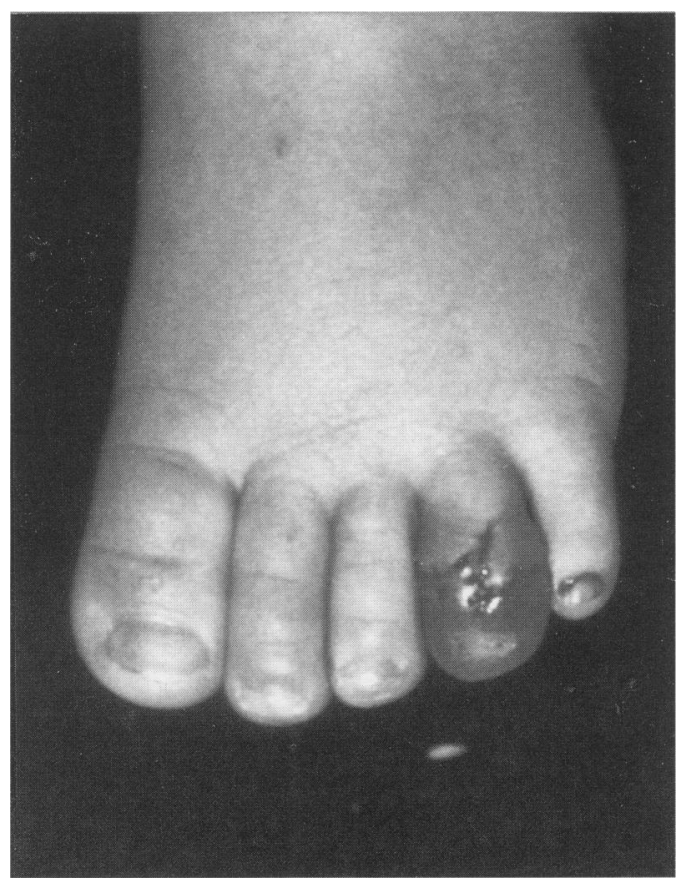

Figure 4 The toe following removal of the hair tourniquet. $A$ dorsal Z-plasty was fashioned. Note reactive hyperaemia.

persists as to the completeness of the removal, especially as the constricting hair cuts through the skin and becomes invisible.

Reported complications of digital tourniquets include tissue loss, flexion deformities, and amputations. Higher rates of complication were found in external genitalia strangulations and these include urethrocutaneous fistulae and gangrene of the glans. ${ }^{1}$

In all cases the possibility of non-accidental injury should be borne in mind, although most appear to have been inadvertent. One piece jump suits and mittens with loose nylon threads have been identified as sources of the ligatures. ${ }^{2}$

1 Barton DJ, Sloan GM, Nichter LS, Reinisch JF. Hair-thread tourniquet syndrome. Pediatrics 1988;82:925-8.

2 Collins AG. Hair-thread tourniquet syndrome [letter]. Aust f Dermatol 1990;31:117-8.

\title{
Weever fish stings: a report of two cases presenting to an accident and emergency department
}

\author{
R S Davies, R J Evans
}

Welsh National

Poisons Unit,

Ward West 5 ,

Llandough Hospital,

Cardiff CF64 2XX

R J Evans

Correspondence to: Dr R J Evans,

Accident and Emergency Department,

Cardiff Royal Infirmary,

Newport Road,

Cardiff CF2 1SZ

\author{
Abstract \\ Two patients are described who suffered \\ weever fish stings and presented to an \\ accident and emergency department. The \\ characteristic symptoms and treatment \\ are described. \\ ( $\mathcal{F}$ Accid Emerg Med 1996;13:139-141)
}

Key terms: weever fish; fish venom; bites and stings; poisonous fish

Weever fish are among the most venomous fish present in the temperate zone. They are found in European coastal waters (Baltic to North Africa), the eastern Atlantic Ocean, and 